\title{
Towards a Noncompliant Pedagogy of the Image: Reading Negentropic Bifurcatory Potentials in Video Images
}

\author{
Urban Film-Making
}

\author{
Masayuki Iwase | ORCID: oooo-0oo2-8635-1906 \\ Department of Educational Studies, the University of British Columbia, \\ Vancouver, Canada \\ miwaseubc@gmail.com \\ Joff P. N. Bradley | ORCID: oooo-0oo2-1036-2246 \\ Faculty and Graduate School of Foreign Languages, Teikyo University, \\ Tokyo, Japan \\ joff@main.teikyo-u.ac.jp
}

\begin{abstract}
The authors explore the noncompliant pedagogy of the image based on their video Autopoietic Veering: Schizo Socius of Tokyo and Vancouver (2021). It is not the kind of trendy modelized video abstract or kinetic presentation eagerly promoted by international publishers; it is a cross-cultural collaborative work intended to generate affirmative temporal ruptures of entropic habitual modes of seeing, memorizing, and thinking of human and nonhuman life in the cities of Tokyo (Japan) and Vancouver (Canada). The authors elucidate Stiegler's (2015b) concept of a "global mnemotechnical system" that stores and produces human memories in vast digital archives and databases (tertiary retentions) through "mnemonic control" (Parisi \& Goodman, 2011). The authors repurpose video images to interrupt and recontrol human perception and memories as "living engines" (Lazzarato, 2006). They foreground the philosophical work of Deleuze, Heidegger, and Virilio to rethink and revive the creative act of "critique" (Foucault, 1997) through "metamodelization" (Guattari, 1995; Manning, 2020); therefore, they plug these apparently incommensurable modes of thinking into their readings of the video's images. They read the images as "time-images" and focus on their five dimensions that possibly activate "spiritual automation" (Deleuze, 1989), which they assess as "negentropic bifurcatory" potentials (Bradley \& Kennedy, 2019).
\end{abstract}




\section{Keywords}

urban film-making - critique - metamodelization - global mnemotechnical system

- proletarianized knowledge - mnemonic control - artificial and living engines

- machinic enslavement - negentropic bifurcation - Deleuze - Heidegger - Virilio

- time-image - lectosign - spiritual automation - zooming-in/out - autistic milieus

- diffractive becoming - radical pedagogy

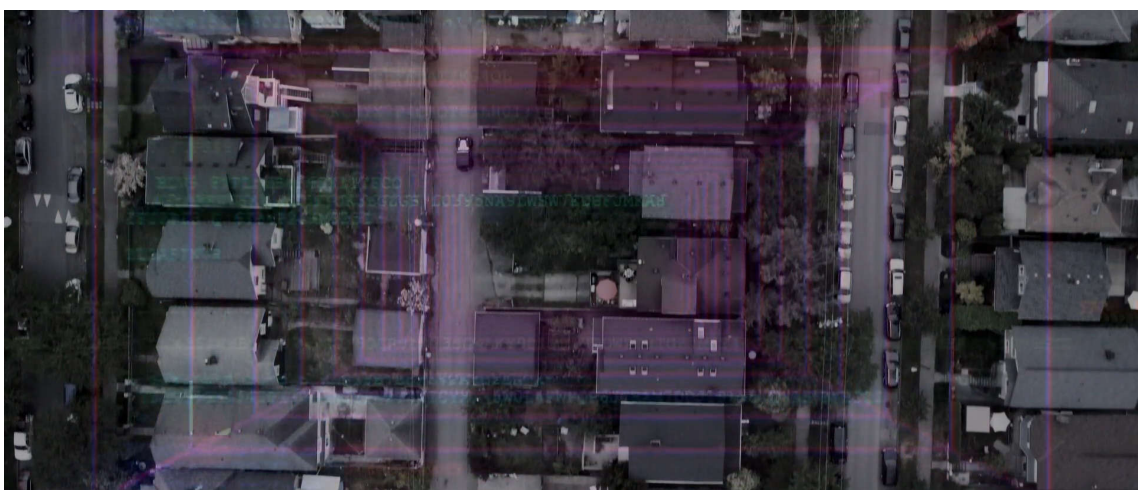

FEATURE This article is based on the film 'Autopoietic Veering: Schizo Socius of Tokyo and Vancouver (2021)', which can be viewed here.

- This article is part of the special topic 'Urban Film-making and Pedagogies of Noncompliance: Posthuman ecologies and the re-imagining of urban life', edited by David Rousell and Laura Trafi-Prats.

We have swallowed our microphones and headsets ... We have interiorized our own prosthetic image and become the professional showmen of our own lives.

BAUDRILLARD, 1995, p. 97

Without pretending to promote a didactic program, it is a matter of constituting networks and rhizomes in order to escape the systems of modelization in which we are entangled and which are in the process of completely polluting us, head to heart.

GUATTARI, 1995, p. 132 


\section{Introduction}

This written experiment and the accompanying video entitled Autopoietic Veering: Schizo Socius of Tokyo and Vancouver (2021) started as a reaction to a barrage of automatic marketing mail which solicited that scholars transform their work into a video abstract or presentation, principally with the aim of simplifying recondite research for the general public. Indeed, in recent years, there has been much interest in using visual abstracts to represent and encapsulate complex ideas and theories, predominantly in the hard sciences; for example, these visuals can represent, through kinetic modelization, the movement of populations, the daily global traffic of the airline industry or the variations of a viral infection. This kinetic modelization has now moved to the humanities. Nowadays, there is increasing interest in, and indeed a market for, the translation of complex ideas expressed in traditional humanities subjects such as economics, sociology and philosophy into video formats. Indeed, publishers such as Taylor \& Francis Group, Springer Nature, and SAGE have been quick to seize upon this trend and advertise aggressively to capture market share in this lucrative business. ${ }^{1}$ They encourage scholars to present their research in the style of a video abstract or kinetic presentation with the aim of increasing scholars' profiles and the visibility of their research, that is, to make their work accessible to the wider public, including policymakers within and beyond their respective fields.

At first glance, a so-called 'good' video abstract or presentation (Informa Group, 2021) seems an innovative and opportune idea. Indeed, there seems nothing inherently wrong with this approach because in the science community, the visual representation and modelization of abstract ideas is heuristic and established scientific methodology. However, the style of video abstracts or presentations has become a business model and revenue stream used by publishers and businesses who often charge extortionate rates for the conversion of these media. The cynics amongst us would say it has become a vanity industry in the humanities. With this in mind, we ask: Why would a scholar in the humanities wish to have their ideas transformed into visual representations in the first place? What, if anything, is lacking with the written word?

1 We refer to the following websites of the respective publishers: Taylor \& Francis (https:// authorservices.taylorandfrancis.com/research-impact/creating-a-video-abstract-for-yourresearch/); Springer Nature (https://www.springernature.com/gp/researchers/publicationpromotion); and SAGE (https://us.sagepub.com/sites/default/files/sage_video_abstractexternal_guidelines.pdf). 
What happens in the transformation from written prose to a video abstract or presentation?

Accordingly, we ask the following questions: why and when should our ideas be converted into a video abstract or presentation in the first place? What is gained, if anything, and what is lost in this process? More than this and more positively perhaps, what is created serendipitously in the conversion process? The latter is what our video presentation inquired into, if not answered. On one level, we argue that the act of conversion into a video abstract or presentation is premised on "tracing" as an act of copying and reproducing something ready-made from a preestablished "model" (Deleuze \& Guattari, 1987, p. xvi). The conversion as such is a reductive modelized act that diminishes or impoverishes the creative and critical potential of video-based educational research. The modelized act of conversion is detrimental to scholars who pursue philosophical writing that inquires into "critique", which Foucault (1997) once articulated as "the art of voluntary insubordination, that of reflected intractability" assuring "the desubjugation of the subject in the context of what we could call, in a word, the politics of truth" (p. 32).

On the other hand, and in response, we think that what we need instead as an alternative to the modelized act is "metamodelization", which according to Guattari (1996b), "appropriates all or part of existing models in order to construct its own cartographies, its own reference points, and thus its own analytic approach, its own analytic methodology" (p. 122, original emphasis). Metamodelization "draws schizoanalytic diagrams of life-living, diagrams that are always more than a passage from here to there, diagrams thick with the resonance of orientations fabulated, of turns not taken, language unscripted" (Manning, 2020, p. 3). With this in mind, we do not trace a preestablished model but attempt to draw creative "lines of flight" (Deleuze \& Guattari, 1987) that deterritorialize the modelized act of conversion, which is an integral part of the axiomatics of what we later describe as a "global mnemotechnical system" (Stiegler, 2015b). We can draw such lines by discordantly or noncompliantly using video, more specifically, video images. We thus insist that the video qua technology of the "pharmakon" embraces both a poisonous and curative mode (Bradley, 2021; also see Stiegler, 2014, 2015b). This is the crux of the matter we endeavor to cast light upon.

What we are interested in is how video images think in/for themselves, how thought relinks to time and temporality virtually through recontrolling human perception and memory, and how something new, uncanny, or futural may come forth from the creative translation of complex ideas into video format. Based on our video project as a cross-cultural collaborative work that explores the characteristics of the noncompliant pedagogy of the image, we explore how 
our video images generate affirmative temporal ruptures of entropic habitual modes of seeing, memorizing, and thinking human and nonhuman life in the cities of Tokyo (Japan) and Vancouver (Canada) and across the different urban time zones that we, the two authors of this writing experiment and producers of the video, inhabit. Our particular interest in video images is our experiment with "a heuristic visual means for rethinking geologic timescales in the time of nonhuman scales" (Bradley, 202ob, p. $5^{-6}$ ). In other words, we attempt to find pedagogical disruptions of the entropic modes of perception and memory in urban populated settings to assess the diminishment of human perception in the nonhuman temporality of the Anthropocene. ${ }^{2}$

We begin by elucidating upon Stiegler's $(2015 \mathrm{~b})$ philosophical concept of the "global mnemotechnical system." He questioned how this entropic system stores and produces human memories in vast digital archives and databases (tertiary retentions) in urban technopoles across the planet (Stiegler, 2015b). We elaborate on the system's core nature by explicating "mnemonic control" (Parisi \& Goodman, 2011). Knowledge produced via a video abstract or presentation arguably functions as either an integral element of the mnemonically controlled and anticipated system or an alternative act of critique. In terms of the latter, we give prominence to the philosophical work of Gilles Deleuze, and the phenomenologies of Martin Heidegger and Paul Virilio who, as thinkers, help to explain the role and prospectus of perception in the time of capital. We made effort to plug these apparently incommensurable modes of thinking into our subsequent readings of our video's images in order to understand the act of critique. We read the video images as 'time-images' and focus on their five dimensions activating 'spiritual automation' (Deleuze, 1989). We conclude by arguing for the importance of metamodelization as a way to conceive of a "radical pedagogy" (Manning, 2015).

Global Mnemotechnical System: Its Nature and Contingency

\subsection{Global Mnemotechnical System and Proletarianized Knowledge}

Information retrieval is fundamental to the operation of what Bernard Stiegler (2015b) called the "global mnemotechnical system" that mobilizes and

2 Aligning with David R. Cole and Karen Malone (2019), our approach to understanding Anthropocene is "a threshold that makes us (re)consider our existence, responsibilities and actions with respect to how we live" (p. 157) in light of the serious consequences of the history of human civilizations entrenched in anthropocentric exceptionalism and concomitant human-nature, nature-culture, subject-object binaries. 
orchestrates information as a commodity in an economic and planetary war for market supremacy. Knowledge as such is written and recorded through a digitized grammatization process and through the exteriorization of tertiary retentions enabled by the techno-capital and pre-emptive power of maximizing non-conscious affective algorithmic intelligence (Parisi, 2019a; Parisi \& Goodman, 2011; Stiegler, 2015b; also see Rouvroy \& Stiegler, 2016). In terms of our project, we wondered what would be lost in the conversion of a good video abstract or presentation into the knowledge appropriated by and integrated into the axiomatics of a global mnemotechnical system.

Stiegler (2015b) argued that the total integration of knowledge paradoxically serves as the "dis-integration of knowledge itself" (p. 168). In other words, it becomes a form of "proletarianized" knowledge (or "disindividuated" knowledge or "anti-knowledge"), oblivious and indifferent to the human, social, ecological, and psychic wreckage brought about by the global marketing system (Stiegler, 2015b, p. 168). Humans who possess and exercise such knowledge become hyper-synchronized "dividuals" or Big Data sets (reduced to sampling, marketing data, archive data, banks of information) and are subsumed and massified in the cybernetic circuits of computation and non-conscious automated cognition (Bradley, 2018, p. 413; also see Deleuze, 1995; Sellar \& Thompson, 2016; Webb et al., 2020). Ultimately then, knowledge as such descends into a closed system of spatiotemporal stasis, homogeneity, and disorder without aim or purpose (Bradley \& Kennedy, 2019; Clough, 2007; Goodman, 2019).

What we mean by entropy pertains to the conditions of knowledge descended into such an aimless or purposeless closed system. Echoing and relating Antoiette Rouvroy and Bernard Stiegler's (2016) question to our concerns, we argue that "[w]hat is lost with this entanglement [in the closed system] is the possibility of critique" (p. 7) and the potential for creative differentiation. What we later articulate as negentropy pertains to the alternative conditions under which the entropic knowledge proliferating in the closed system gets disrupted by the introduction of video images that can possibly generate new stimuli to our memories and habit so as to rethink and revive the creative act of critique and differentiation.

\subsection{Information Retrieval and Mnemonic Control}

We further argue that the axiomatics of a global mnemotechnical system marshal and secure the calculation, anticipation, and governance of future time precisely through the autopoiesis of algorithmically learned and ruled machinic temporalities (Webb et al., 2020; also see Stendera, 2015). Governed by calculation, time becomes entropic of futural possibility. The futural prospectus as such is curtailed through cybernetic strategies of what Luciana 
Parisi and Steve Goodman (2011) emphasized as "mnemonic control," or a form of preemptive artificial governmentality of people's lives by affectively tapping into virtual memories and simultaneously orchestrating prospective perceptions (also see Webb et al., 2020). In this sense, futurity is capital so long as it is "not just some predictive simulation, but the investment in future feedback, an investment in intuitive, prehensive anticipation, part of a ceaseless betting on future desires" (Parisi \& Goodman, 2011, p. 165).

Importantly, what is required for such mnemonic control is the reconfiguration of the relations between short-term and long-term memory, which is equivalent to the relations between perception and memory (Parisi \& Goodman, 2011). Parisi and Goodman's (2011) elucidation of the mnemonic control adopted in the contemporary hyper-branding matrix is instructive:

Contemporary branding culture, for example, sets out to distribute memory implants, which provide the recipient with the sense of the already enjoyed, encouraging repeated consumption, a repetition of a memory the recipient hasn't had. The operation of power through branding seeks to remodel long-term memory via a kind of time anomaly. Branding, when it occupies the shortest possible time-spans, is a parasite on the dynamic of short-term intuition - the coexistence of the past-present-future - ceaselessly affecting long-term memory by instigating movement in the neurophysiological plasticity of the brain. Branding potentiates long-term memories through the stirring of new synaptic connections, re-routing memories that are immediately familiar. Long-term memories are continuously reassembled in nonlinear combinations by the immediacy of short-term memory.

PARISI \& GOODMAN, 2O11, pp. 172-173

Accordingly, futurity hinges on controlling such technical apparatuses as digital technologies, which are "artificial engines" to exteriorize flows of desires as eventual knowledge at a distance) (Lazzarato, 2006, pp. 186). However, it must also revolve around people's perception and memory as "living engines" that are coaxed into immediately retrieving, recognizing, and extending flows into habitual actions that are simultaneously both present and future-oriented (Lazzarato, 2006, p. 186).

\subsection{Possibilities of Recontroling Perception and Memory as "Living Engines"}

In the global mnemotechnical system, vital moving forces are living engines such as perception and memories subject to mnemonic control. These are 
"pre-personal, pre-cognitive, and preverbal forces (perception, sense, affects, desire)" that overdetermine "supra-personal forces (machinic, linguistic, social, media, economic systems, etc.)" (Lazzarato, 2014, p. 31). Following Maurizio Lazzarato (2014), we argue that mnemonic control gives rise to "machinic enslavement," which is an efficient, amorphous dispositif (apparatus) producing subjectivity through the affective mobilization of such pre-personal, pre-cognitive, and pre-verbal forces alongside, beyond, and underneath a multiplicity of material and semiotic elements.

Intriguingly, it is helpful to take into account Félix Guattari's (200o, p. 45) emphasis on the contingent nature of a-signifying semiotics:

At the heart of all ecological praxes there is an a-signifying rupture, in which the catalysts of existential change are close at hand, but lack expressive support from the assemblage of enunciation; they therefore remain passive and are in danger of losing their consistency - here are to be found the roots of anxiety, guilt and more generally, psychopathological repetitions ... In the scenario of processual assemblages, the expressive a-signifying rupture summons forth a creative repetition that forges incorporeal objects, abstract machines and Universes of value that make their presence felt as though they had been always "already' there, although they are entirely dependent on the existential event that brings them into play.

GUATTARI, 2OOo, p. 45

It is precisely through a-signifying ruptures that molecular components can vibrate expressive elements for creative differentiation or becoming as newness and futurity. The global mnemotechnical system itself is a vast "singular existential territory" immanently bestowing "a power of heterogenesis, that is, of opening singularizing, irreversible processes of necessary differentiation" (Guattari, 1995, p. 55). Deleuze (1992) also posited that "[t]he new is not supposed to mean the same as the fashionable but, on the contrary, the variable creativity which arises out of [dispositifs themselves]" (p. 163). Thus, reappropriation can evolve from not only leveraging technical dispositifs such as video technologies and images (understood as artificial engines), but also from modulating people's perception and memories as living engines. As Guattari (1996a) stressed, such reappropriation, which is the pursuit of "micropolitics" and "molecular revolutions," "begins with very immediate, daily, individual preoccupations, yet remains connected to what happens at the social level, and even, why not, at the cosmic level" (p. 70). Such quotidian reappropriation is precisely what our urban filmmaking found. 

to Virilio

We regard video technologies as artificial engines, and video images, which enable the interruption and recontrol of human perception and memories, as living engines, despite, and thanks to, the immanent conditions created by machinic enslavement. The prime writing task for us and our video Autopoietic Veering: Schizo Socius of Tokyo and Vancouver is to generate affirmative temporal ruptures of human perception and memories governed by the dominance of entropic knowledge proliferating under the global mnemotechnical system. In other words, the possibility of generating what Joff P. N. Bradley and David Kennedy (2019) emphasized as a "negentropic bifurcation" (also see Bradley, 2018, 2020a, 202 Ob; Stiegler, 2015a, 2018) is vital to interruption and recontrol. As "the [pharmacological] moment of struggle against entropy" (Bradley \& Kennedy, 2019, p. 7), negentropic bifurcatory potentials entail undoing the proletarianization of knowledge and transgressing "the predictions of the search engines, the intoxication with SNS, and the manipulation of life under algorithmic control" (Bradley, 2020a, p. 448, original emphasis). We conceive of the possibility and viability of the generation of negentropic bifurcation in relation to the work of Gilles Deleuze, Martin Heidegger, and Paul Virilio. In what follows, we highlight the philosophers' relevant ideas.

\subsection{Deleuze's Philosophical Accounts of the Time-Image}

We are interested in Gilles Deleuze's (1989) philosophical accounts of the time-image for our experiment in making a video for negentropic bifurcatory potentials. His ontology inspires new ways of presenting time under the conditions of the collapse of the sensory-motor schema. In on-screen images, time-images (both visual and sound) are perceived as 'false' or 'aberrant' movements that call forth "an anteriority of time that it presents to us directly, on the basis of the disproportion of scales, the dissipation of centres and the false continuity of the images themselves" (Deleuze, 1989, p. 37, our emphasis). Typically, the viewer who inhabits the contemporary hyper-branding matrix (with the everyday bombardment of images publicized through platforms including sNSs) instinctively perceives and immediately extends actualized on-screen images into his/her habitual actions without the suspension of his/her sensory-motor perception-action "interval" (Martin-Jones, 20o6, our emphasis). There is "a greater degree of success" in resuming the viewer's perception-action interval whenever pure memories of the past (or attentive recollections) are brought forward without an attentive effort of mind and instead through a 'match' between the memories of the past and the perceived images 
on-screen to extend them to his/her habitual bodily actions (Martin-Jones, 2006, p. 53).

By extension, as Deleuze's (1994) "three syntheses of time" 3 explicates, the success in suspending the viewer's perception-action interval requires controlling his/her habits and memory. Habit, which pertains to what Deleuze (1994) articulated as the "first synthesis" of time, refers to the passively or unconsciously learned practices (e.g., gestures, movements, actions) repetitively performed by the subject in the living present. As in Henry Bergson's (1929) reversed cone signals, habit manifests itself bodily through the subject in the present as the most contracted point of an entire past that coexists with the present in an infinity of levels and degrees of contraction and relaxation (also see Deleuze, 1989, 1994). It follows then that the manifestation and retention of habit is dependent upon the subject's past experience and learning as real memories, which survive within his/her independent recollections and for his/her subsequent attentive recognition. The subject's memory pertains to what Deleuze (1994) articulated as the "second synthesis" that predominantly governs his/her habit. Moreover, what Deleuze (1994) articulated as the "third synthesis" is concerned with "futures," which are "untimely," undetermined, and open. Such futures emerge when/if the subject as an actor, author, or agent "erases the hold of the passive synthesis of the first" - that is, of his/her governed habit in the colonizing lived present, and when/if the past becomes "a failed condition" in which anticipated futures are entirely freed from chronological past-present-future arrangements (Williams, 2011, p. 105).

Given Deleuze's three syntheses of time, "the continuity of the sensory-motor subject" remains intact so long as "there is almost no time lag, no interval, in which an attentive recollection can intervene between what is perceived and the mechanical setting into motion of the action that is performed upon it" (Martin-Jones, 2006, p. 51). What interests us here is the opening up to virtual conjunctions and new possibilities - that is, the future as the third synthesis

3 Deleuze's (1994) three syntheses of time expanded on Bergson's (1929) philosophy of image, matter, and duration. Our understandings of Deleuze's (1994) three syntheses of time is based on the summary he gave in Difference and Repetition: "The first synthesis, that of habit, constituted time as a living present by means of a passive foundation on which past and future depended. The second synthesis, that of memory, constituted time as a pure past, from the point of view of a ground which causes the passing of one present and the arrival of another. In the third synthesis, however, the present is no more than an actor, an author, an agent destined to be effaced; while the past is no more than a condition operating by default. The synthesis of time here constitutes a future which affirms at once both the unconditioned character of the product in relation to the conditions of its production, and the independence of the work in relation to its author or actor" (p. 94). 
of time. It is imperative here to consider the unsuccessful retainment of the subject's or viewer's memories or active recollection by stretching the perception-action interval and interrupting his/her automatic responses to transmitted on-screen images (both visual and auditory). In doing so, certain stimuli that can short-circuit the viewer's sensory-motor habits are necessary to generate virtual connections to "Aionic" time, which according to Deleuze (1990), exists in a "pure empty form of time" (p. 165) or "demented time" (Deleuze, 1994, p. 88).

With Deleuze's three syntheses of time in mind, we then assert that video technologies and images are artificial engines which can generate such stimuli, and that they are germane to the question of negentropic bifurcatory potentials. Lazzarato's (2019) post-Bergsonian account of screen media's affective capacities to generate such stretching and short-circuiting is instructive:

I suggest the hypothesis that the technologies of time imitate, in their operations and in their products, the various syntheses of time (the conservation, passage, and splitting-emergent of time) and that, through the operations of contraction-relaxation, they work on the conditions of the production of affective force. The matter that these technologies contract is, as in Bergson, time-matter (material vibrations) and the different temporal satisfactions of memory. I use the term imitation to signify the electronic and digital technologies operate like the material and spiritual syntheses in Bergson: they crystallize time. Video and digital technologies can therefore be understood as technologies that imitate perception, memory, and intellectual labor.

LAZZARATO, 2019, pp. 65-66

This hypothesis suggests that screen medium qua video is capable of synthesizing (or crystalizing) time through the editing of images (as Deleuzian time-images). This modulates the viewer's habitual actions (as material synthesis) and attentive recollection (spiritual synthesis, memory recall, and intellectual labor) (Lazzarato, 2019). His emphasis on "imitation" refers precisely to the affective capacities of actualized on-screen edited images (both visual and sound) that operate as stimuli - that is, negentropic bifurcations - sensed by the viewer to travel in the temporal mazes of Aionic time.

Ultimately, our experiment in making video images corresponds to what Deleuze (1989) emphasized as the "spiritual automaton," or "the unconscious in thought," productive of "a shock to thought, communicating vibrations to the cortex, touching the nervous and cerebral system directly" (p. 156, original emphasis). The spiritual automaton induced by video images can potentially 
disrupt automation in the age of the algorithmic machine. It contests preemptive decision making and anticipatory futures (Parisi, 2019b). Echoing Parisi (2019b), we assert that the spiritual automaton of our video can potentially generate Deleuze's third synthesis of time and the "cinematic machine" which

concerns not the carrying out of tasks and the efficiency of functions, but it deploys indeterminate sensory or aesthetic components through which it enters the larger arrangements of our senses, our bodies and brains. As a non-verbal automation of images, cinema exposes the role of time and space in thinking, whereby chronological and geometrical orders are intersected with topological configurations and overlapping temporalities. Instead of being tied to human consciousness, cinema reveals the inhuman activities in the circuit of thinking as shocks in brains. The automated series of images coincides with a supra-conscious dimension of being involved in the molecular automatisms that process information and perform thinking autonomously, without conscious thought or cognition.

PARISI, 2019b, p. 107

\subsection{Heideggerian Existential of 'Us-without-the-World'}

The noncompliant images of our video we read shortly explore life without the world of others, a life without the world, of being outside the world and not with a world (Deleuze, 1984). Our mobile containment is also an opportunity to think about the concept of "us-without-the-world" - that is, the world subtracted from the self. It is as Martin Heidegger (1995) said in the Fundamental Concepts of Metaphysics (p. 176). Like the animals, we are poor in world: we are somehow subtracted from the world, deficient; we have a deficient mode of being (defizienter Modus). In Being and Time, Heidegger (1962) wrote that being-alone is a deficient mode of Dasein's being-with (p. 157) but in the existential of "us-without-the-world," we are not of the world as the structure of Mitsein or being-with is remote, distant. Our video experiment brings this out heuristically.

With respect to the zooming in and zooming out of perception, our video thinks in itself phenomenological forms of autistic, hermetic, monadic perception in the time of the pandemic. The autistic commuter dwells within a milieu that skirts across scales and registers of life: organic and inorganic, human and inhuman. The autistic commuter is consumed and intoxicated by its portable object and mesmerized by shapes, multiple languages, and flickering intensities, a milieu of light, color, movement, sound, and mobile contexts. Yet in this complex ecology of autistic perception, there is a potential for a different 
form of movement as the body shifts and recomposes itself in accordance with exuberant intensities and events.

From the act of zooming in and zooming out of presence that we find in Heidegger, we extrapolate from this and say: in the time of the Covid-19 pandemic, we are constantly being zoomed in and zoomed out of perceptual modes of intimacy and extimacy; we are being constantly zoomed in and zoomed out of an in/outside field. We ruminated on the idea of how video zooms in and out of alterity in the time of the pandemic. Through our smartphones, cameras, drones, PC equipment, and sound recording devices, we wondered how to return subjectivity to itself as a source of creation and sufficiency. Video thinking is one source of experimentation and noncompliance, as it seemed to us that the conversion of ideas into a video abstract or presentation promoted by international publishers was entirely alien and deficient. Something serendipitous came forth instead. In this regard, what is more interesting is to explore how zoom and scala can help to rethink movement as such (Woods, 2014). New modes of process of subjectivation can reshape the collective possibilities of imagination in relation to the nonhuman environment (Guattari, 1995, 2000).

From the shared planetary trauma of the pandemic, what is revealed in the breakdown of the everyday is a tendency to eliminate remoteness, to undermine the intimacy of where one dwells. Intimacy has absconded also. There is a deadly ipseity of the self. In Being and Time, Heidegger (1962) said that being alone is a deficient mode of being-with as there is no leaping over to the other. Or in our words, there is no leaping over to the other in the zooming in and out of technology. If it were the case that there could be a leaping over towards the other through technology-mediated solicitude, then the other would become transparent to itself and thus emancipated, as Heidegger (1962) said. But no. In the zooming in and zooming of technology, there is a commandeering of the other, a control of the other; we are left marooned, existentially quarantined by this unfreedom. Autistic perception is a field perception which apprehends the complex relational patterning of our zooming experience. Here Virilio's phenomenology resonates.

\subsection{Virilio's Pedagogy of Scale and Image}

In Bradley's (2020b) work, Paul Virilio (1994, 1996, 1997, 1999, 2005, 2010, 2012; also see Virilio et al., 2011) was used to appreciate changing conceptions of scale and image. Bradley (2020b) made the case for a Virilian pedagogy of scale and image by arguing that this allowed us to better grasp the decentering of human conceptions of time and space as we come to better understand the vastness of cosmological space and time. His argument should read in tandem with Guattari's (1995, 2000; also see Guattari \& Negri, 2010) work on ecosophy 
and Stiegler's $(2018,2019)$ work on negentropy to show how Virilio's critique of the diminishment of perspective diverges from their respective approaches to forge an arresting pedagogy of the image vis-à-vis geographical and ecological conceptions of Earthly spatial and temporal scales. The perceived poverty of Earthly perspective is read in the light of a scalar perspectivism which understands the enormity of the universe and humanity's microscopic place within it. Considering Virilio's concern with the changes in scale that manifest in the time of globalization, Bradley (2020b) questioned how an applied dromology (that is, the philosophy of speed) may work alongside both Guattari's schizoanalytic and ecosophical research and Stiegler's pharmacology of the image in a way that mounts a robust and unique critique of the mental pollution of the image as such. Bradley (2020b) claimed that the diminishment of world perspective devastates our understanding of the cosmos and light; the Virilian pedagogy of scale and image is therefore essential for understanding the poverty of scale and perspective and the reduction of the world to nothing.

In trying to kinetize Virilio's phenomenology of the bodily comportment, our video images enable us to read a phenomenological process which grasped distance as something that human perception now struggles to comprehend. Our video finds that perception is increasingly automatic, inhuman, and led by artificial intelligence. Indeed, in the time of capital, according to Virilio, the collapsing of distance affects the human body which is in perpetual motion. Bodies move in and on different modes of transport autistically, isolated, and bodies sojourn within a ritournelle of perception - oral, melodic: sounds from headphones, beeps from cash registers, train ticket gates, flashes from seat reservations, recorded announcements on buses, jingles and refrains at train stations, tannoy announcements within a local community or from a nearby school. Other sounds emerge, like motorbikes and motorcars as they whizz by, sounds of the insect and bird kingdom, chatter from neighbors nearby, beeps indicating a text from your boss demanding this or that paperwork, or calls from numerous automated sNs devices (Bradley, 2014a, 2014b, 2016). Dimensions

The video images of Autopoietic Veering: Schizo Socius of Tokyo and Vancouver juxtapose a number of shots to present the posthuman ecologies in which human and nonhuman bodies are affecting and affected by one another. There are aerial shots captured "transmaterially" (Munster, 2014, p. 159) through the nonhuman flow of modulated signals transmitted by a drone's flights. There are 
shots of buzzing and tranquil topographies of cityscapes and our local urban milieux captured through a mirrorless DSLR camera mounted on a gimbal stabilizer and by a handheld smartphone camera placed on the front basket of a bicycle. There are also super close-up macro-lens shots of interkingdoms in these territories.

With the video juxtaposing these shots together with a polyphony of music and various recorded sound and noise, we are interested in finding pedagogical disruptions of the entropic modes of perception and memory of urban populated settings and in assessing the diminishment of human perception in the nonhuman temporality of the Anthropocene. In doing so, we attempt to read the video's time-images. More specifically, we read the spiritual automation induced by "opsigns" and "sonsigns" which according to Deleuze (1989), are adjudged pure visual and audio images emerging in what he called the "anyspace-whatever," that is, an indeterminate singular space where linkages are made infinitely for virtual conjunctions and new possibilities (p. 109). Deleuze (1989) described such opsigns and sonsigns as the "lectosign" as a sub-variety of the time-image that "must be 'read' as much as seen" (p. 334).

Deleuze (1989) asserted "to read is to relink instead of link; it is to turn, and turn round, instead of to follow on the right side: a new Analytic of the image" (p. 245; also see Deamer, 2016). For him, reading an actualized on-screen edited image entails relinking "what is expressed in a proposition independent of the relationship of this to its object" (Deleuze, 1989, p. 284). This account corresponds to his ideas of sensing an event, which is "not what occurs (an accident)" but must be "inside what occurs, the purely expressed" by "signal[ing] and await[ing] us" (Deleuze, 199o, p. 149). Events are incorporeal and impassive effects or results of bodies with their tensions, physical qualities, actions, and passions, and the corresponding "states of affairs" (Deleuze, 1990, p. 4). Accordingly, the reading in which we engage does not rely on 'interpretation,' which places the subject at the center as the 'autonomous thinking subject' who examines our video images as if there is an essential discoverable truth that provides the justification for the very act (Masny, 2012). ${ }^{4}$ We insist that, despite our application of the phenomenologies of Heidegger and Virilio, the reading we invite the viewer to invest in is "intensive" and "immanent" reading

4 Our approach to reading our video images is thus not compliant with what St. Pierre (2016) characterized as "conventional humanist qualitative inquiry," a qualitative methodological structure that cannot exist without cogito celebrated by Descartes and elaborated by many other Western Enlightenment philosophers. The ontological basis for this conventional approach to inquiry privileges human beings at the centre as Cartesian cogito and a subject 'I' and produces many different representational forms and categories of thought, including subject/object, human/nonhuman, and world/thing (St. Pierre, 2015). 
of sense and events that "[extend] the power to read differently and to think differently, to go beyond what is to what could be, the virtual-actual interaction: difference and becoming" (Masny, 2009, p. 183; also see Iwase, forthcoming). The sense and events are best characterized with Deleuze and Guattari's sense of "haecceity," which is:

a non-subjective assemblage of humans, time, space, physical objects, and everything else: 'It should not be thought that a haecceity consists simply of a décor or a background that situates subjects ... It is the entire assemblage in its individual aggregate that is haecceity ... that is what you are, and ... you are nothing but that' ...

DELEUZE \& GUATTARI, 1987, pp. 262, cited in ST. PIERRE, 2011, pp. 618

In what follows as a concluding part of this essay, we pinpoint five dimensions that can be read as spiritual automata activated through our video images: (1) scales of zooming-in and zooming-out, (2) the world-without-other as autistic milieu, (3) sounds, (4) colors and relations as haptic, (5) speeds as diffractive becoming. Reading each dimension involving opsigns and sonsigns, or more specifically lectosigns, possibly invites the viewer to encounter haecceities that short-circuit his/her sensory-motor habits by generating virtual connections to Aionic time - that is, the unthought, spiritual automata, and negentropic bifurcatory potentials. With this in mind, we shall pose several overarching questions regarding the five dimensions and share some of our sample readings of each. Following (Masny, 2009), we ask: What can each dimension of the video do and "produce"? How does it "work" (p. 182)? Answering this, we sense and relink each dimension to the unthought, thus not intending to orient the viewer towards interpreting meaning behind the video images in any straightforward didactic way, for instance, by asking: What does each dimension mean? Rather, what we are aiming for is a disruption to everyday entropic modes of thinking, and it is here that Heidegger's theory of inconspicuousness of the ready to hand and Virilio's theory of the accident help to inform our video experiment.

\subsection{1st Dimension: Scales of Zooming-In and Zooming-Out}

Google zooms in on our position; its satellites guide a singular projection in represented vectors, somehow representing the to-ing and fro-ing in real time. Google Lens provides data on the everyday world: for example, the best fruit in the local prefecture, the quality of organic produce, information on supermarket bread, the price of the purchase, the remaining credit on the person's 
phone. We are notified of shops and restaurants in our local area, as well as the local temperature, the traffic issues that may affect a singular journey. We are zoomed out of our regular milieu through views of Tokyo Bay from a third eye and information on the geography and relief of the wider area. We note the vast greenery of the landscape in one instant and then in another the zooming in on the greyness of the commuter belt. Through augmented reality, the world is teeming with information. Each thing is singular. Augmented reality supplements and intensifies the direct perception of the transcendental field of becoming. Video augmentation is verily a different way to comprehend the world - a new Universe of reference and collective hallucination and imagination in the language of Guattari (2000).

Cocooned in funk, through the zooming in and zooming out of technology informed by the Heideggerian existential of "us-without-the-world" (Heidegger, 1995), the world is dissevered further. Yes, the world comes to the viewer, and the viewer becomes a far-seer of the world. The zooming in and out of the world of technology brings the far-ness of the world to close proximity. Technology zooms in, brings others from far-ness into nearness, to close proximity, manifesting anxiety and paranoia in the very bringing to nearness of that which is far away. Dwelling is no more. What is far away is brought nearer and nearer to the extent that its present to handedness is disclosed. In withdrawal there is a de-severance of both the self and world

\subsection{2nd Dimension: the World without Others as Autistic Milieus}

Our noncompliant video images explore life without the world of others, a life without the world, of being outside the world and not with a world (Deleuze, 1984). Our mobile containment is also an opportunity to think about the concept of "us-without-the-world" - that is the world subtracted from the self, where the structure of everydayness has gone. The abstract, impersonal and automatic signals, alerts, messages, announcements of everyday work and the commuting world have all fallen silent. We move but no longer move. We travel but no longer travel. We become hermetic. Monadic. There is no outside. The collapse of this everydayness reveals through its present that the world is not there around us; we are alone.

The autistic commuter dwells within a milieu that skirts across scales and registers of life, organic and inorganic, human and inhuman. The autistic commuter is consumed and intoxicated by its portable object and mesmerized by shapes, multiple languages and flickering intensities, a milieu of light, color, movement, sound, and mobile context. Yet in this complex ecology of autistic perception, there is a potential liberation in movement as the body shifts and 
recomposes itself in accordance with exuberant intensities and events. A new world beckons.

Our video images are therefore consistent with research on the "social recluse” (hikikomori/引きこもり) (Saitō, 2016). What we were effectively exploring is a thought-experiment regarding the non-human world outside. Laden with headphones strapped to our heads and with smartphones in our hands, when we are traveling on different modes of transport, bicycle, bus, train, we are autistically immune to other people and cocooned away from the wider world. Our video images may invite the viewer to sense the connection between autistic and noncompliant perception when we venture outside in the world without others we are inhabiting.

\subsection{3rd Dimension: Sounds}

The sounds the viewer hears throughout our video are characterized as "nondiegetic," that is, being rendered "external to the direct presentation of the [video]" (Deamer, 2016, p. 167; also see Chion, 1994). The sounds do not summon up their sources or presence, though heard in relation to the video's actualized on-screen visual images. Throughout the video, the off-screen nondiegetic sounds are presented as a polyphonous cacophony of recorded ambient music (i.e., warm, haunting, soothing drones) and various types of background sounds and noises including computer system and gadget sounds (e.g., mouse clicks); scheduled automated voices announced at multiple Tokyo train stations; the second author's daily commute on the Chūō-Sōbu Line (Japanese: 中央 - 総武緩行線) and at those train stations (in 錦系町, 神田, 東京, 御茶ノ水, 新宿); the first author's stroll in the vibrant, groovy east side of Vancouver; swarming birds chirping and resolute river streamflow; and recurring ocean waves.

The polyphonic cacophony of the sounds involves "selection, elimination and extraction, in order to prevent the interior forces of the earth from being submerged, to enable them to resist, or even to take something from chaos across the filter or sieve of the space that has been drawn" (Deleuze \& Guattari, 1987 , p. 311). The earth appearing at the very beginning and end of our video, where the camera goes into the involution of a becoming-bee of the flower as well as a becoming-flower of the bee, signals as such. It resonates with an "egg" as a plane of immanence and as a virtual, intensive, and actualized full body (Deleuze, 1994, 2003, 2004; Deleuze \& Guattari, 1983, 1987). The earth as an egg is a "body without organs," which is not "an empty body stripped of organs" but "a living body all the more alive and teeming once it has blown apart the organism and its organization" (Deleuze \& Guattari, 1987, p. 30). The polyphonic cacophony deriving from the assembled music, sounds, and noises 
reveals the forces of the earth: "[t]he forces of air and water, bird and fish, thus become forces of the earth" (Deleuze \& Guattari, 1987, p. 321). The earth as such is the actualization of its "dramatic spatio-temporal" embryogenetic processes of "individuation" (e.g., cellular migration, stretching, invagination) precipitated by and incarnating the virtual condensation of aleatory "singular" events (e.g., creation of nucleus and cytoplasm after miraculous fertilization) (Protevi, 2012).

We characterize such a polyphonic cacophony in the earth as "rhythms," which are passages expressive of the communications or difference between spatiotemporal "milieus," which are coded, transcodable, and transductable human and nonhuman beings (Deleuze \& Guattari, 1987). These rhythms are expressive of the local milieu that produces territories to be reterritorialized or deterritorialized (Deleuze \& Guattari, 1987). The viewer, who is likely exposed to the polyphonic cacophony operating as sonsigns, may sense rhythms or refrains (ritournelle) "that have been territorialized because they have become expressive - and have become expressive because they are territorializing" (Deleuze \& Guattari, 1987, p. 317). ${ }^{5}$ The swarming birds chirping, the cawing of a murder of crows, the resolute river and pond streamflow, and the recurring ocean waves sing in unison to mark their territories among the computer system and gadget sounds, the scheduled automated voices at the Tokyo train stations the second author hears during his daily commute, and the worrisome siren of an ambulance brought into contact with the first author during his stroll in East Vancouver.

\subsection{4th Dimension: Colors and Its Relations as Haptic}

The prominent color of the video is gray with sporadic tints of blue, at least in the first half. Perceiving such a color in a sensory-motor schema, we tend to link it to some nuanced apocalyptic imagery of our inhabitation in the hectic urban life of Tokyo and Vancouver, which is dictated by the techno-capital pre-emptive power of nonhuman algorithmic intelligence. The video subsequently shows a sequence of images of Cedar, Hemlock and other trees,

5 It should be worth noting here that one of the most recent films that we think extraordinarily incorporates sonsigns to invite the viewer to paradoxically sense sounds as cacophony and refrains is Memoria (2021), which was written and directed by a Thai artist and filmmaker Apichatpong Weerasethakul with starring Tilda Swinton. The film is one of those few exemplars of effectually making the spectator experience spiritual automata. Incorporating carefully calibrated clamorous and susurrate sonic entities that operate as sensory forces, the film images, especially sonsigns, of Memoria exquisitely yet enigmatically present the simultaneity and indeterminacy of the past and the present, the living and the dead, and terrestrial and the other (Bradshaw, 2021; Keogan, 2021). 
mountains, a forest, ocean waves, a sky with clouds, and such species as ants strolling on the stems of thorny Himalayan blackberry flower stems, a tenacious spider on its web, a koi family in the pond of the first author's house, and bees gathering nectar from the flowers around the house. Perceiving this sequence in a sensory-motor schema, we tend to link it to a more or less linear passage between cold apocalyptic cityscapes and warm exuberant, reinvigorated colorful habitats.

The viewer may nevertheless relink the colors of the video to virtual conjunctions and new possibilities. As opsigns, the colors are now not so much linked with the already actualized inherent physical state or property of a city - tree, ocean, sky, or species as 'being' as a noun - but relinked instead with each "attribute" as an "extra-being" or 'becoming' understood as a verb or an infinitive that signals the dynamisms of its actualization and self-differentiation (Deleuze, 1990, p. 21; also see Lambert, 2011). Echoing Deleuze (1990), we may sense the green of the trees and forests in the video as the 'tree green' or 'forest greens' signaling "a mixture of things, a mixture of tree and air where chlorophyll coexists with all the past of the leaf" in order "to green" (p. 21).

Our video images thus arrange colors as extra-beings or becomings and importantly relinks and relates them with the degree of intensiveness and extensiveness as the passage oscillates between the coldness of the apocalyptic cityscapes and the warmness of the natural habitats. Through such vibrational, intensive qualities, the viewer is invited to perceive the colors in the video as not only optical but also "haptic" (Deleuze, 2003). Deleuze (2003) noted that the haptic "does not designate an extrinsic relation of the eye to the sense of touch, but a 'possibility of seeing [regard],' a type of a vision distinct from the optical" (p. 189). The colors of the video operate as haptic as much as optical conduits, so haptic sense is another way of seeing and reading the colors of the video. As Deleuze (2003) asserted, "[I]t is color, and the relations between colors, that form [the visual world rejoining] haptic world and haptic sense" (p. 138). In this sense, echoing Erin Manning (2008), we assert that "coloring comes through virtuality - we never see it as such" (p. 329). Specifically, "[t]o perceive [colors] is always to see more than the actuality of appearance - it is to see-with the relational tendencies that gather to propose a oneness of form or figure" (Manning, 2008, p. 327).

\subsection{5th Dimension: Speeds as Diffractive Becoming}

Our video involves the sequence of those images of the second author's bicycle-train ride. His ride signals the "molar line" of a rigid segmentarity that codes and the overcodes social fields and the confinement of his existence and movement to a "striated space" in which the trajectories of his ride are subordinated to fixed points or positions and identities (Deleuze \& Guattari, 1987). 
This sequence gradually becomes confronted and interfered with through the sequence of images of a multitude of ocean waves overlapping and spreading out as they encounter other waves as obstructions of their singular paths. The viewer in a sensory-motor schema likely interprets these two contrasting sequences as binary to create two incommensurable and incompatible worlds and realities. Nevertheless, he/she may likely paradoxically sense the indiscernibility and undecidability of these two image worlds or realities in the intermezzo.

The multitude of self-differentiated haphazard ocean waves that recurrently lap on the beach and soak up human footprints without a trace resonate with the liminal in-betweenness. The speeds and movements of ocean waves (accompanied by sounds) are germane to so-called "diffraction", which 'does not produce "the same" ... not map where differences appear, but rather maps where the effects of difference appear' (Haraway, 1992, p. 300, original emphasis; also see Barad, 2007, 2014). Diffraction as such signals "the relations of difference among people and among humans, other organisms, and machines than historical domination, incorporation of parts into whole, paternalistic and colonial protection, symbiotic fusion, antagonistic opposition, or instrumental production from resource" (Haraway, 1992, p. 300). The diffractive ocean waves recurrently lapping on the beach and soaking up the footprints resonate with Trinh Minh-ha's (1997) sense of an "inappropriate/d other" as that which nothing can appropriate and that which is inappropriate, thus affirming difference but unsettling every definition of otherness that is predetermined and prearranged (p. 418; also see Barad, 2014; Grzinic, 1998; Haraway, 1992).

The virtual idea of such diffraction nuanced by the multitude of nonhuman encountering and overlapping ocean waves vis-à-vis the merging human footprints into the ocean signal bodies' affective encounters and exertion to act upon the power of other bodies, that is, "becoming" (Deleuze \& Guattari, 1987, p. 256). Such becoming as affects emerges in "a zone of indetermination, of indiscernibility" where we no longer know if we are humans, animals, plants, languages, none of these, or beyond these (Deleuze \& Guattari, 1987, p. 173). This is the zone where bodies of whatever kind quest for the "becoming-imperceptible" or "becoming-everybody/everything," thereby making any body no longer distinguishable and discernible from particular privileged points or positions (Deleuze \& Guattari, 1987, pp. 279-28o).

Much work has gone into offering to the reader and the viewer a noncompliant image of thought. But more than this, we have put forward a pedagogy 
of the noncompliant image through the kinetic medium. Much work has gone into putting into conversation a series of thinkers who do not necessarily function in an integrated whole: the phenomenologies of Heidegger and Virilio, for example, do not necessarily work in tandem with the schizoanalysis of Deleuze and Guattari, nor with the work of Stiegler and Lazzarato. Our intention was to use their respective architectonics as a means to metamodel a conceptual schema that can be read alongside our video experiment and beyond the modelized act of fancily converging our ideas and thoughts into a video abstract or presentation. We thus offer our video to the viewers in the hope that the five proposed dimensions of the video images affect us to move and think that there is the possibility to remodel a different order of things out of the perilous, schizophrenic/autistic, and bleak reality we inhabit as the corollary of the axiomatics of a global mnemotechnical system.

Accordingly, our wish is to continue assessing to what extent our video, along with our sample readings of it based on the five dimensions, might successfully generate affirmative temporal ruptures of entropic habitual modes of seeing, memorizing, and rethinking of human and nonhuman life in the urban cities of Tokyo and Vancouver in the nonhuman temporality of the Anthropocene. The video images may or may not activate negentropic bifurcations as spiritual automata in the body and mind of the viewer who is firmly lodged in sensory-motor schemata and/or who inhabits elsewhere other than these cities because of the absence of any match between his/her memories of the past and the images perceived on-screen to extend them to his/her habitual bodily actions. We are interested in whether and in what ways the viewer might sense the involution of the indiscernibility and indeterminacy of the second author's bicycle and train ride as 'a becoming-bicycle of the train,' as well as 'a becoming-train of the bicycle'; of the bee and the flower as 'a becoming-bee of the flower,' as well as 'a becoming-flower of the bee'; and of the polyphonous cacophony of the recorded music and the various types of background sounds and noises re/deterritorializing one another.

Our hope is that any of the proposed five dimensions of our video images read as lectosigns potentially and even temporarily short-circuit the viewer's sensory-motor habits by generating virtual connections to Aionic time (Deleuzian third synthesis) and contribute to assessing the diminishment of his/her/our perception in the nonhuman temporality of the Anthropocene. The reader and the viewer are welcome to contribute to our experiment with the video's negentropic bifurcatory potentials by sharing their comments on the website where it is posted and through any available social media network where such feedback as active expressive a-signifying rupture could potentially play out as a catalyst of existential change. In this sense, the noncompliant pedagogy of the 
image based on our video project "does not decide in advance what is useful" and "is skeptical of the very idea that we should know in advance where learning will take us" (Manning, 2015, p. 206). Echoing Manning (2015), we shall plug our pedagogy into a 'radical pedagogy' engaged with a "pragmatics of the uselessness," that is, "what is in the world, right now, and speculative in the sense that it is open to transformation by potentializing force of where study can take us" (p. 207). Therefore, our video project is not intended for any measure of conclusion yet; there is no beginning, nor end in it, as long as it engages in diffractive becoming.

\section{References}

Barad, K. (2014). Diffracting diffraction: Cutting together-apart. Parallax, $20(3)$, 168-187. DOI: 10.1080/13534645.2014.927623.

Barad, K. (2007). Meeting the universe hallway: Quantum physics and the entanglement of matter and meaning. Duke University Press.

Baudrillard, J. (195). The virtual illusion: Or the automatic writing of the world. Theory, Culture and Society, 12(4), 97-107. DOI: 10.1177/026327695012004007.

Bergson, H. (1929). Matter and memory (N. M. Paul \& W. S. Palmer, Eds.). George Allen \& Unwin Ltd.

Bradley, J. P. N. (2014a). The Zerrissenheit of subjectivity. Tamkang Review, 44(2), 37-62. Bradley,J.P.N. (2014b). Machinic dopamine junkies and the (im)mobile walk(less)MAN. In R. Bogue, H. Chiu, \& Y. L. Lee (Eds.), Deleuze and Asia (pp. 121-143). Cambridge, UK: Cambridge Scholars Publishing.

Bradley, J. P. N. (2016). Guattari and Pachinko: Deadly ritournelle, himatsubushiTinguely machines. 한국비평이론학회 학술대회 발표집, (2): 1-22.

Bradley, J. P. N. (2018). Cerebra: "All-human", "all-too-human", "all-too-transhuman". Studies in Philosophy and Education, 37, 401-415. Dor: 10.1007/s11217-018-9609-4.

Bradley, J. P. N. (2020a). Negen-u-topic becoming: On the reinvention of youth. Educational Philosophy and Theory, 52(4), 443-454. Dor: 10.1080/o0131857.2019. 1619171.

Bradley,J. P. N. (2020b). On the prospects of Virilio's pedagogy of the image. Educational Philosophy and Theory, 53(7), 706-718. DoI: 10.1080/00131857.2020.1761330.

Bradley, J. P. N. (2021). On the gymnastics of memory: Stiegler, positive pharmacology, and illiteracy. New Zealand Journal of Educational Studies, 56, 5-22. Dor: 10.1007/ s40841-021-00196-2.

Bradley, J. P. N., \& Kennedy, D. (2019). On the organology of utopia: Stiegler's contribution to the philosophy of education. Educational Philosophy and Theory, 42O-432. DOI: 10.1080/oo131857.2019.1594779. 
Bradshaw, P. (2021, November 10). Memoria review - Apichatpong Weerasethakul and Tilda Swinton make a dream team. The Gurdian. https://www.theguardian.com/ film/2021/jul/15/memoria-review-apichatpong-weerasethakul-tilda-swinton.

Chion, M. (1994). Audio-visions: Sound on screen (C. Gorbman, Trans.). Columbia University Press.

Clough, P. (2007). Introduction. In M. Hardt \& P. Clough \& J. Halley (Eds.), The affective turn: Theorizing the social (pp. 1-33). Duke University Press.

Cole, D. R., \& Malone, K. (2019). Environmental education and philosophy in the Anthropocene. Australian Journal of Environmental Education, 35(3), 157-162. DoI: $10.1017 /$ aee.2020.5.

Deamer, D. 2016). Deleuze's cinema books: Three introductions to the taxonomy of images. Edinburgh University Press.

Deleuze, G. (1984). Michel Tournier and World without others. Economy and Society, $13(1), 5^{2-71}$.

Deleuze, G. (1989). Cinema 2: The time-image (H. Tomlinson \& G. Robert, Trans.). University of Minnesota.

Deleuze, G. (1990). The logic of sense. Columbia University Press.

Deleuze, G. (1992). What is a dispositif? In Michel Foucault: Philosopher (T. J. Armstrong, Trans.) (pp. 159-168). Harvester Wheatshearf.

Deleuze, G. (1994). Difference and repetition. (P. Patton, Trans.). Columbia University Press.

Deleuze, G. (1995). Negotiations 1972-199o (M. Joughin, Trans.). Columbia University Press.

Deleuze, G. (2003). Francis Bacon: The logic of sensation (D. W. Smith, Trans.). Continuum.

Deleuze, D. (2004). Desert islands and other essays. Semiotext(e).

Deleuze, G., \& Guattari, F. (1983). Anti-oedipus: Capitalism and schizophrenia. (B. Massumi, Trans.). University of Minnesota Press.

Deleuze, G., \& Guattari, F. (1987). A thousand plateaus: Capitalism and schizophrenia. (R. Hurley, M. Seem \& H. R. Lane, Trans.). University of Minnesota Press

Foucault, M. (1997). What is critique? In S. Lotringer \& L. Hochroth (Eds.), The politics of truth: Michel Foucault (pp. 23-82). Semiotext(e).

Goodman, A. (2019). Black magic: Fragility, flux and the rewilding of art. In E. Manning, A. Munster, \& B. M. S. Thomsen (Eds.), Immediation I (pp. 134-16o). Open Humanities Press.

Grzinic, M. (1998). Shifting the boarder of the other: An interview with Trinh T. Minh-ha. https://www.heise.de/tp/features/Shifting-The-Borders-of-The-Other-3441351.html.

Guattari, F. (1995). Chaosmosis: An ethico-aesthetic paradigm (P. Bains \& J. Pefanis, Eds.). Indiana University Press. 
Guattari F. (1996a). Chaosophy: Soft subversions (S. Lotringer, Ed.) (D. L. Sweet \& C. Wiener, Trans.). Semiotext(e).

Guattari, F. (1996b). The Guattari reader (G. Genesko, Ed.). Blackwell Publishers.

Guattari, F. (2000). The three ecologies. I. Pindar \& P. Sutton (Eds.). The Athlone Press.

Guattari, F. (2013). Schizoanalytic cartographies (A. Goffey, Trans.). Bloomsbury.

Guattari, F., \& Negri, A. (2010). New lines of alliance, new spaces of liberty. Autonomedia.

Haraway, D. (1992). The promises of monsters: A regenerative politics for inappropriate/d others. In L. Grossberg, C. Nelson, \& P. A. Treichler (Eds.), Cultural studies (pp. 295-337). Routledge.

Heidegger, M., MacQuarrie, J., \& Robinson, E. S. (1962). Being and time. Basil Blackwell.

Heidegger, M. (1995). The fundamental concepts of metaphysics: World, finitude, solitude (W. McNeill \& N. Walker, Eds.). Indiana University Press.

Informa Group. (2021). Creating a video abstract for your research: Introduce your research in your own words. Taylor \& Francis Group. Retrieved from https://author services.taylorandfrancis.com/research-impact/creating-a-video-abstract-foryour-research/.

Iwase, M. (forthcoming). Minor videos and becoming-Japanese: Problematizing $[c o][$ existence] policies and envisioning alternative futures of young migrants in Japan. [Unpublished doctoral dissertation], the University of British Columbia.

Keogan, N. (2021, October 10). The persistence of Memoria. Paste. https://www. pastemagazine.com/movies/memoria-review/.

Lambert, G. (2011). Expression. In C. J. Stivale (Ed.), Gilles Deleuze: Key concepts (2nd ed.) (pp. 33-43). Routledge.

Lazzarato, M. (2006). The concepts of life and the living in the societies of control. In M. Fuglsang \& B. M. Sørensen (Eds.), Deleuze and the social (pp. 171-19o). Edinburgh University Press.

Lazzarato, M. (2014). Signs and machines: Capitalism and the production of subjectivity. J. D. Jordan (Trans.). Semiotext(e).

Lazzarato, M. (2019). Videophilosophy: The perception of time in post-Fordism. J. Hetrick (Ed., Trans.). Columbia University Press.

Manning, E. (2015). 10 propositions for a radical pedagogy, or how to rethink value. Inflexions, 8, 202-210.

Manning, E. (2008). Coloring the virtual. Configurations, 16(3), 325-346. DoI: 10.1353/ con.0.0063.

Manning, E. (2020). Radical pedagogies and metamodelings of knowledge in the making. Critical Studies in Teaching and Learning, 8(SI), 1-16. DoI: 10.14426/cristal. v8iSI.261. http://www.inflexions.org/radicalpedagogy/main.html\#Manning.

Martin-Jones, D. (2006). Deleuze, cinema and national identity: Narrative time in national contexts. Edinburgh University Press. 
Masny, D. (2009). What's in a name?: MLt. In D. Masny \& D. R. Cole (Eds.), Multiple literacies theory: A Deleuzian perspective (pp. 181-192). Sense Publishers.

Masny, D. (2012). What is reading? A cartography of reading. In D. Masny \& D. R. Cole (Eds.), Mapping multiple literacies: An introduction to Deleuzian literacy studies (pp. 71-92). Continuum.

Munster, A. (2014). Transmateriality: Toward an energetics of signal in contemporary mediatic assemblages. Cultural Studies Review, 20(1), 150-167. DoI: 10.5130/csr. v2oi1.3836.

Parisi, L. (2019a). Critical computation: Digital automata and general artificial thinking. Theory, Culture \& Society, 36(2). DoI: 10.1177/0263276418818889.

Parisi, L. (2019b). Media ontology and transcendental instrumentality. Theory, Culture \& Society, 36(6). DOI: 10.1177/o263276419843582.

Parisi, L., \& Goodman, S. (2011). Mnemonic control. In P. Clough \& C. Willse, (Eds.), Beyond biopolitics: Essays on the governance of life and death (pp. 163-176). Duke University Press.

Protevi, J. (2012). Deleuze and life. In D. W. Smith \& H. Somers-Hall (Eds.), The Cambridge companion to Deleuze (pp. 239-264). Cambridge University Press.

Rouvroy, A., \& Stiegler, B. (2016). The digital regime of truth: From the algorithmic governmentality to a new rule of law. La Deleuziana, 3, 6-29. https://www.doaj.org/ article/o1436a34946145oba4bebf82ofbdedc9.

Saitō, T. (2016). Hikikomori bunkaron [Cultural theory of social recluse]. Chikumashobō. Sellar, S., \& Thompson, G. (2016). The becoming-statistic: Information ontologies and computerized adaptive testing in education. Cultural Studies - Critical Methodologies, 16(5), 491-501. DoI: 10.1177/1532708616655770.

Stendera, M. (2015). Being-in-the-world, temporality and autopoiesis. Parrhesia, 24, 261-284.

Stiegler, B. (2014). What makes life worth living: On pharmacology. (D. Ross, Trans.). Polity Press.

Stiegler, B. (2015a). Organology of dreams and archi-cinema. The Nordic Journal of Aesthetics, 24(47), 7-37. DOI: 10.7146/nja.v24i47.23053.

Stiegler, B. (2015b). States of shock: Stupidity and knowledge in the twenty-first century. (D. Ross, Trans.). Polity Press.

Stiegler, B. (2018). The neganthropocene. (D. Ross, Ed., Trans.). Open Humanities Press.

Stiegler, B. (2019). The age of disruption: Technology and madness in computational capitalism. Polity Press.

St. Pierre, E. A. (2011). Post qualitative research: The critique and the coming after. In N. K. Denzin \& Y. S. Lincoln (Eds.), The SAGE qualitative research (pp. 611-625). SAGE.

St. Pierre, E. A. (2015). Practices for the "new" in the new empiricisms, the new materialisms, and post qualitative inquiry. In N. K. Denzin \& M. D. Giardina (Eds.), Qualitative inquiry and the politics of research (pp. 75-95). Routledge. 
St. Pierre, E. A. (2016). The empirical and the new empiricisms. Cultural Studies Critical Methodologies, 16(2), 111-124. DOI: 10.1177/1532708616636147.

Trinh, T. M. (1997). Not you/like you: Postcolonial women and the interlocking questions of identity and difference. In A. McClintock, A. Mufti, \& E. Shohat (Eds.), Dangerous liaisons: Gender, nation, and postcolonial perspectives (pp. 415-419). London, UK: University of Minnesota Press.

Virilio, P. (1994). The vision machine (J. Rose, Trans.). Bloomington, IN: Indiana University Press.

Virilio, P. (1996). Cybermonde, la politique du pire. Interviews with Philippe Petit. Les Editions Textuel.

Virilio, P. (1997). Open sky (J. Rose, Trans.). Verso.

Virilio, P. (1999). Politics of the very worst (S. Lotringer, Trans.). Semiotext(e).

Virilio, P. (2005). City of panic. (J. Rose, Trans.). Berg.

Virilio, P. (2010). The university of disaster (J. Rose, Trans.). Cambridge, UK: Polity Press.

Virilio, P. (2012). The administration of fear (A. Hodges, Trans.). Semiotext(e).

Virilio, P., Brausch, M., \& Turner, C. (2011). A winter's journey: Four conversations with Marianne Brausch. Seagull Books.

Webb, P. T., Sellar, S., \& Gulson, K. N. (2020). Anticipating education: Governing habits, memories and policy-futures. Learning, Media and Technology, 45(3), 284-297. DoI: 10.1080/17439884.2020.1686015

Williams, J. (2011). Gilles Deleuze's philosophy of time: A critical introduction and guide. Edinburgh University Press.

Woods, D. (January 01, 2014). Scale Critique for the Anthropocene. The Minnesota Review, 2014(83), 133-142. 